\title{
The impact of cognitive rehabilitation with RehaCom software on attention improvement in patients with traumatic brain impairment
}

\author{
Golam Reza Chalabianloo $^{1}$, Rana Ghorbanzadeh Bavil Oliyei ${ }^{*}$ iD, Farhad Mirzaei ${ }^{3}$
}

\begin{abstract}
1. Associate Professor of Neuroscience, Department of Psychology, Faculty of Education and Psychology, Azarbaijan Shahid Madani University, Tabriz, Iran

2. MSc Student of Cognitive Science-Cognitive Psychology, Faculty of Humanities and Education, Tabriz Islamic Azad University. Tabriz, Iran
\end{abstract}

3. Assistant Professor of Neurosurgery, Department of Neurosurgery, Faculty of Medicine, Tabriz University of Medical Sciences, Tabriz, Iran

Recieved: 28 Jun. 2019

Revised: 30 Apr. 2020

Accepted: 16 May. 2020

\section{Keywords}

Cognitive rehabilitation

Attention

Traumatic brain injury (TBI)

\section{Corresponding author}

Rana Ghorbanzadeh Bavil Oliyei, MSc Student of Cognitive Science-Cognitive Psychology, Faculty of Humanities and Education, Tabriz Islamic Azad University. Tabriz, Iran

Email: Ranabavil@yahoo.com

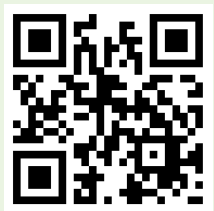

doi.org/10.30699/icss.22.3.48

\section{Abstract}

Introduction: Traumatic brain injury (TBI) is one of the most major causes of disability, especially cognitive problems and mortality worldwide. The present study aims to investigate the effect of cognitive rehabilitation for improving cognitive function with RehaCom software in patients with traumatic brain injury.

Methods: The sample of the present study consisted of 40 patients with TBI selected using purposive sampling and randomly assigned in experimental and control groups $(n=20)$. The results were analyzed using multivariable analysis of covariance (MANCOVA). Research tools included RehaCom cognitive rehabilitation software and continuous performance test (CPT-II). The rehabilitation software was given to the experimental group for eight weeks and three sessions per week for 30 minutes to perform the intervention.

Results: The results showed that cognitive rehabilitation training with RehaCom software significantly improved divided attention $(\mathrm{P}<0.01)$ and continuous attention $(\mathrm{P}<0.05)$ in the experimental group.

Conclusion: The results of this study showed that cognitive rehabilitation with RehaCom software improves the attention of patients with traumatic brain injury and can be used as a complementary treatment method.

Citation: Chalabianloo Gh, Ghorbanzadeh Bavil Oliyei R, Mirzaei F. The impact of cognitive rehabilitation with RehaCom software

on attention improvement in patients with traumatic brain impairment. Advances in Cognitive Sciences. 2020;22(3):48-57. 


\title{
تاثير توانبخشى شناختى با نرمافزار رهاكام بر بهبود توجه در بيماران آسيب تروماتيك مغزى
}

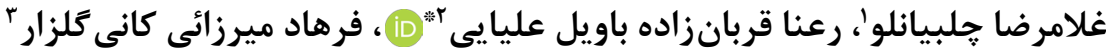

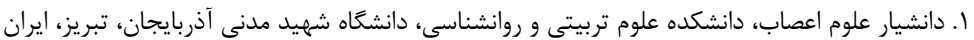

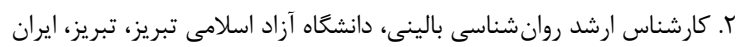

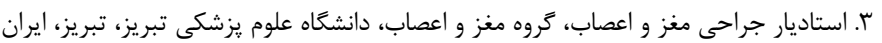

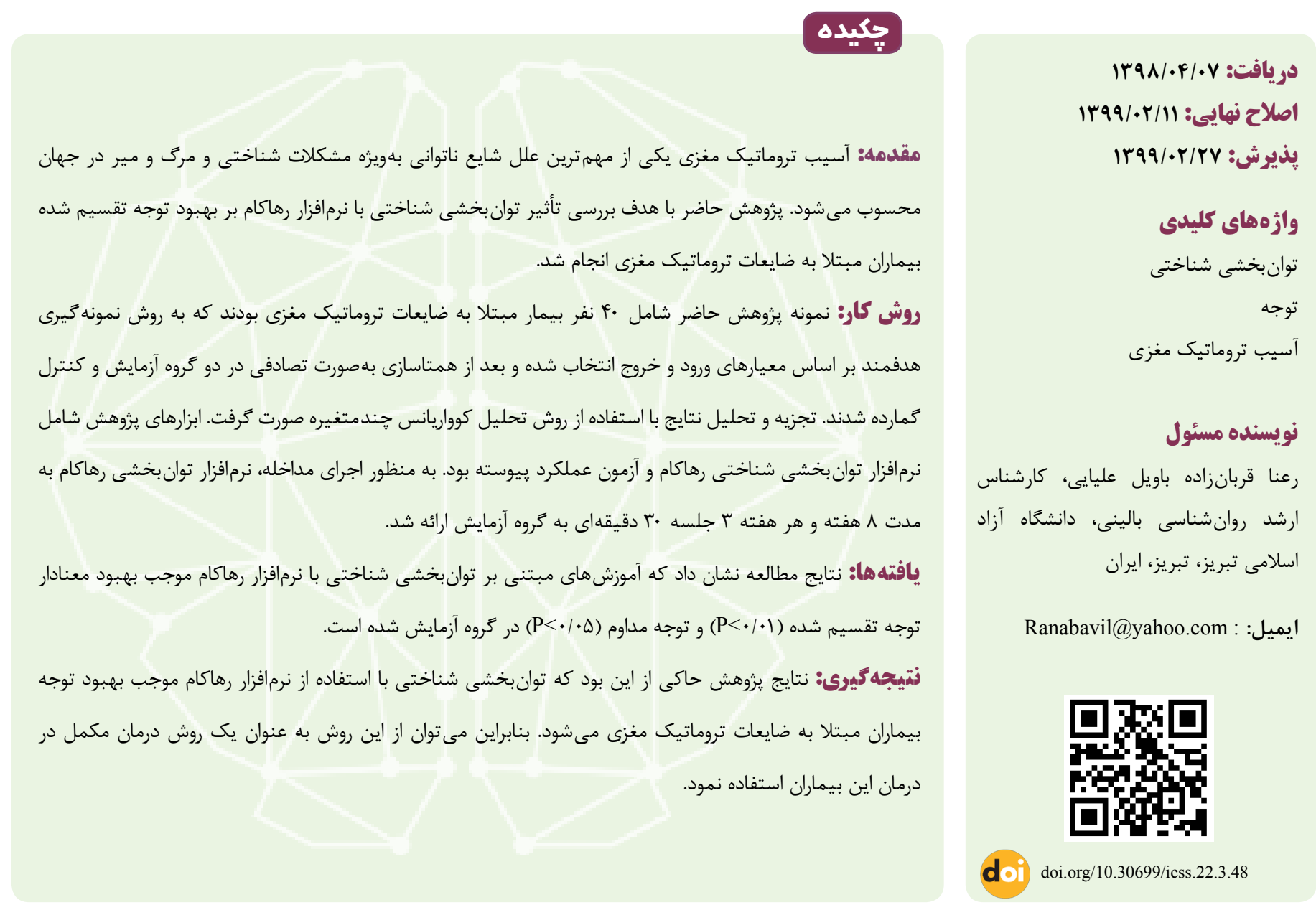

مقلدمه

مىشود كه علائمى از قبيل كاهش آكاهى و هوشيارى، از دست دادن حافظه، اختلالات عصبىروانشناختى و حتى مرى را به همراه دارد (Y). در ايران آسيب مغزى در رتبه دوم مرگ و مير ناشى از ضربه به سر و تروما قرار دارد و به عنوان يكى از علل عمده ناتوانى در درازمدت

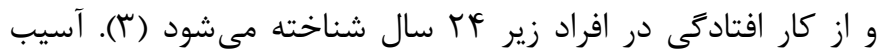

آسيب تروماتيك مغزى (Traumatic brain injury) كه از آن تحت عنوان إيدمى خاموش نيز ياد مىشود، در حال حاضر يكى از مهممترين نخرانىهاى مرتبط با سلامت، در سطح بينالمللى مى باشد (1). بر اساس تعاريف، آسيب تروماتيك مغزى به آسيب اكتسابى بافت مغز به واسطه يك نيروى خارجى با شدت هاى مختلف از ملايمم تا شديد اطلاق 
نرمافزار رهاكام در بهبود حافظه فعال، سرعت يردازش و افسردىى بيماران مبتلا به سكته مغزى استان تهران در سال لو را را مورد تاييد

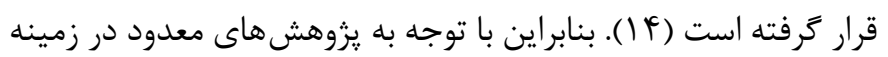

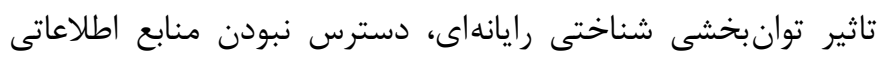

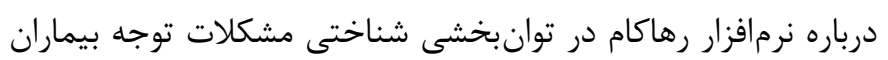

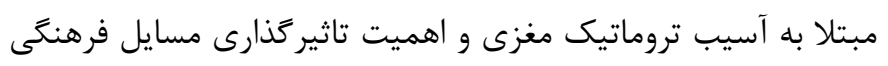
بر عملكردهاى شناختى بر آن شديم بررسى تاثير توانبخشى شناختى

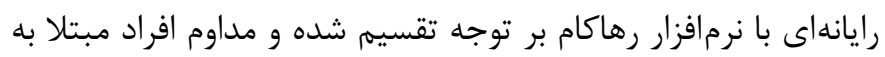
آسيب تروماتيك مغزى بررسى نماييه.

\section{روش كار}

يزوهش حاضر نيمهآزمايشى با طرح يِيشآزمون و پِ آزمون با ليست

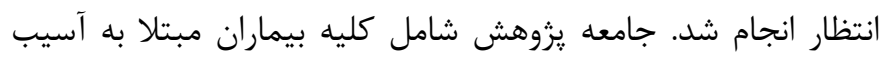

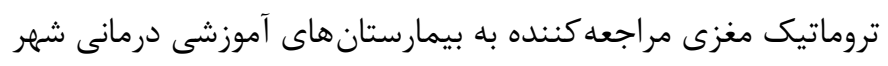

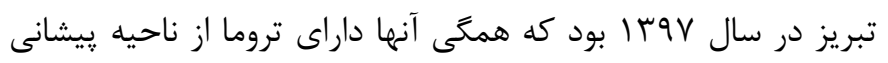

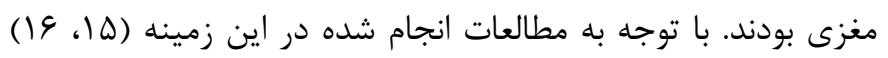

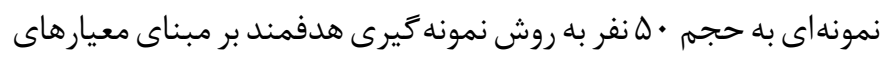
ورود و خروج انتخاب شده و به صورت تصادفى در دو گروه آزمايش و ليست انتظار جايكزين شدند. در نهايت به دليل عدم همكارى برخى از شركت كنندگان و به دليل برابرسازى تعداد افراد هر دو گروه، دادهاى لهاى

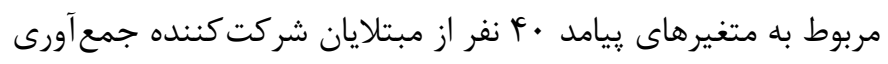

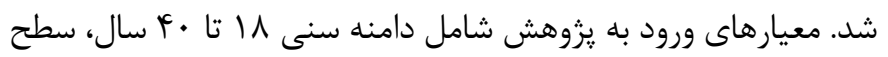

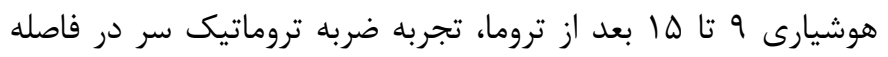

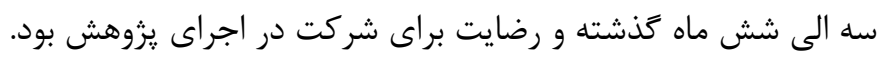

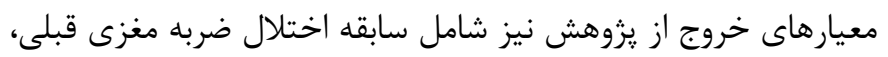

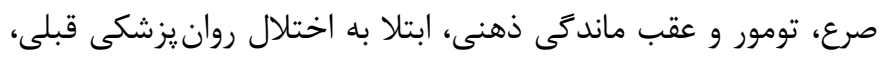
مصرف مواد مخدر و معلوليت حسى_حركتى ناشى از ضربه كه باعث تداخل در اجراى نرمافزار توانبخشى شناختى بود. به منظور اجراى

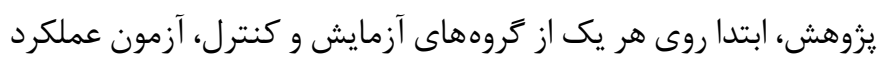

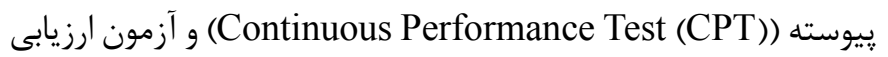
توجه تقسيم شده نرمافزار رهاكام به اجرا درآمد (مرحله يِيشآزمون).

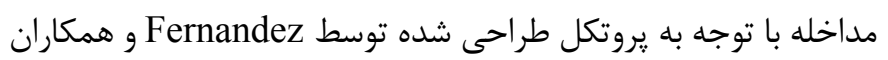

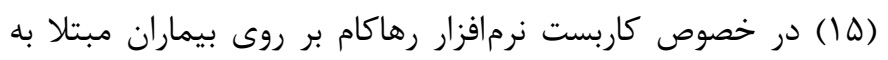

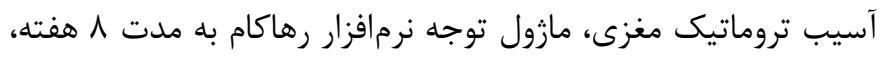

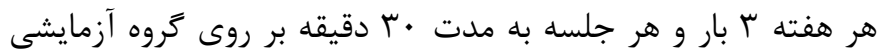
اعمال شد. گروه ليست انتظار نيز، مداخلهاى دريافت نكردند (مرحله

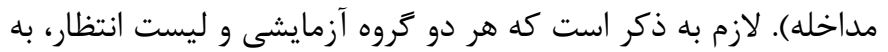

مغزى با عوارض فيزيكى، عاطفى و هيجانى، يادگيرى، شناختى و غيره همراه است (f). با وجود اهميت نقايص فيزيكى، يكى از مهرمترين

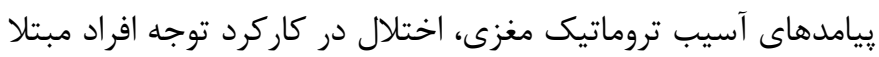

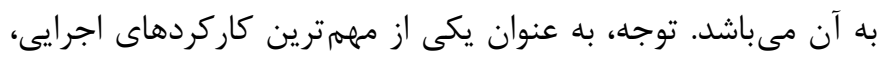

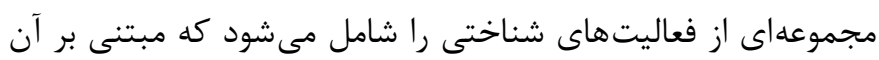
فرد محرك هاى درونى و بيرونى را دريافت و يردازش مىنمايد (ه). Beaulieu-Bonneau

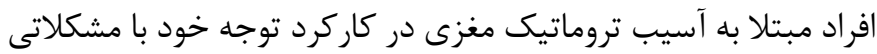
مواجهه هستند (9). همجنين Richard و همكاران در مطالعه خود به بررسى شبكههاى عصبى مرتبط با توجه مداوم در افراد مبتلا به

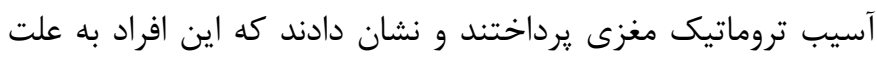

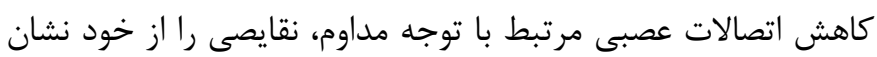

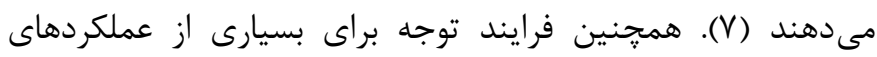

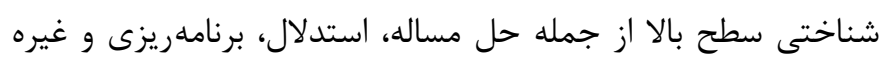

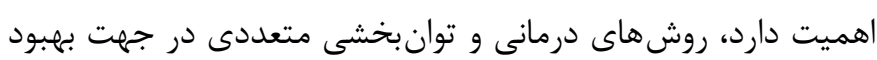
اين بيماران مطرح شده است كه در قالبهاى مختلفى مثل استفاده از روشهاى واقعيت مجازى (^) و توانبخشى شناختى مبتنى بر رايانه (9) ارائه مى شوند. علاوه بر ابزارهاى مطرح شده، يكى از معروفترين

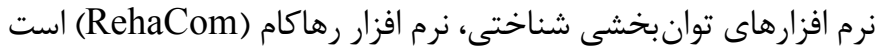

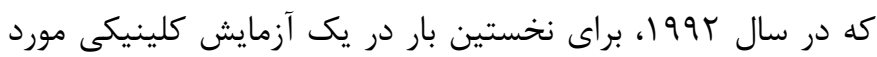

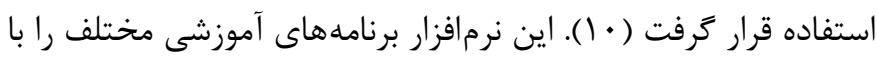

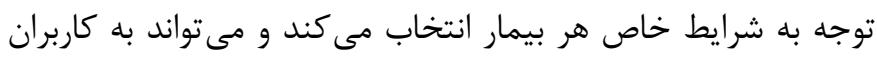

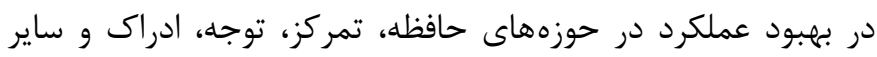

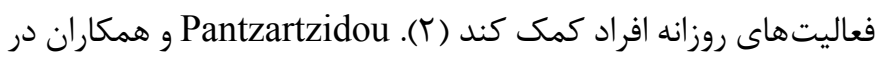
يزوهش خود به بررسى تاثير توانبخشى شناختى با استفاده از نرمافزار رهاكام در بيماران مبتلا به آسيب تروماتيك مغزى يرداختند و نشان دادند كه توانيى توجه و تمركز كروه آزمايش بعد از ع ماه استفاده

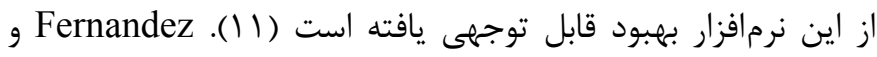
همكاران نيز تاثير توانبخشى شناختى با استفاده از نرمافزار رهاكام

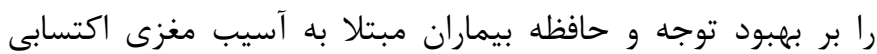
مورد بررسى قرار داده و به اين نتيجه دست يافتند كه توجه متهد متمركز

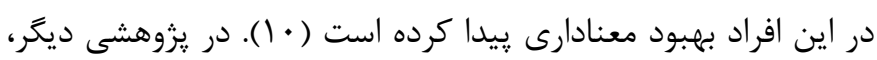

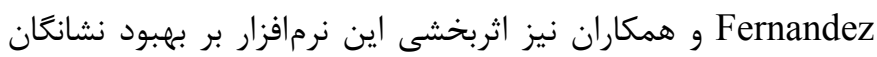

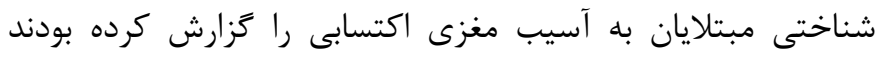
(T) Mohammadi ( ). در مطمكاران اثربخشى نرمافزار رهاكام بر بهبود توانايىهاى شناختى بيماران اسكيزوفرنى مورد تأييد قرار

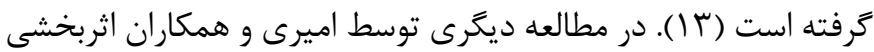


انتخابى، توجه تقسيم شده و غيره را هدف قرار مى دهد و آنها را متمايز مى كند (IV). در يزوهش حاضر نسخه اصلى اين نرمافزار از موسسه علمى داج خريدارى شده است.

آزمون عملكرد پييوسته (CPT-II): آزمون عملكرد يِيوسته يك

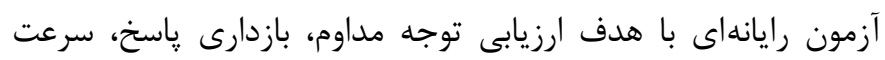

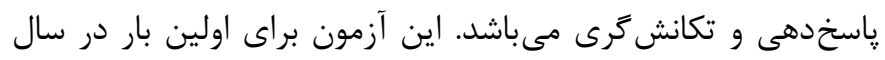
1990 توسط Rosvold تهيه شد و به سرعت مقبوليت عام يافت (1) (1).

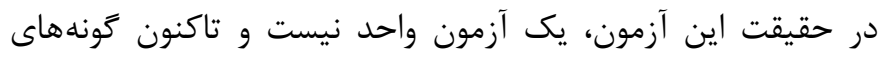
مختلفى از آن جهت اهداف درمانى يا يزوهشى تهيه شده است. فرم فارسى اين آزمون كه از طريق رايانه اجرا مىشود. داراى اعداد فارسى لـى دانى به عنوان محرك است. در طول اجراى اين تكليف، مجموعهاى از اعداد بر روى صفحه رايانه ارائه مى گردد و آزمودنى مى بايست به تمامى اعداد، به جز عدد 9 با فشار دادن كليد مربوطه در صفحه كليد واكنش نشان إنان

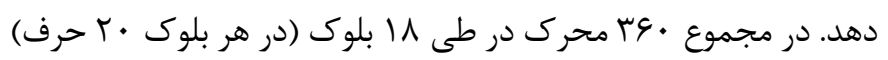

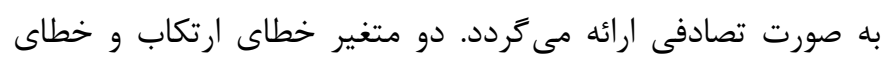

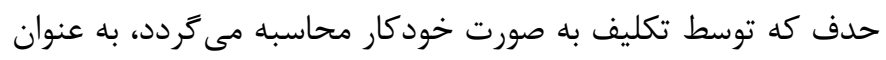
نمره آزمودنى در اين تكليف لحاظ كرديد. روايى اين آزمون در ايران توسط هاديان فرد و همكاران هنرمند بررسى شده است. آنها ضرايب اعتبار بازآزمايى براى قسمتهاى مختلف اين آزمون در دامنهاى بين

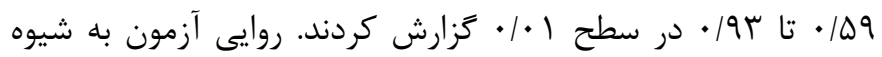
روايىسازى ملاكى از طريق مقايسه كروه بهنجار و ير تحرى همراه

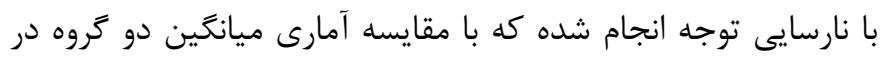

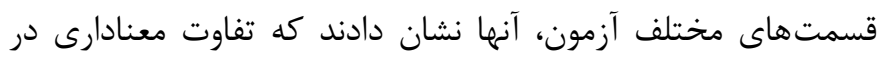
عملكرد اين دو كروه وجود دارد (9 (1).

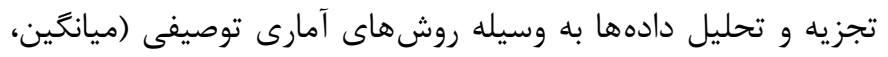
انحراف معيار، فراوانى و درصد) و آزمون T مستقل به وسيله نرمافزار

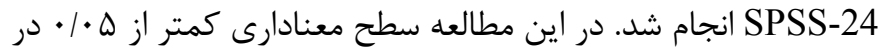

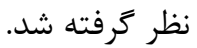

\section{يافته ها}

مطابق با جدول I، VD درصد شركت كنند

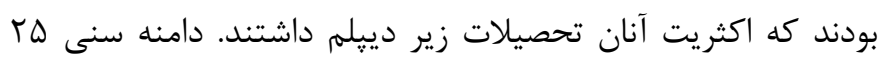

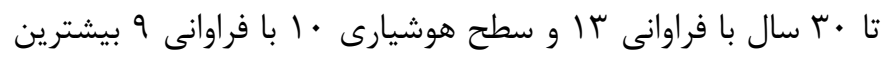
فراوانى شركت كنندكان حجم كروه نمونه را به خود اختصاص دادهاند. علاوه بر اين، مندرجات جدول ا نشان مى دهد كه توزيع دامنه سنى و ميزان هوشيارى بين دو گروه آزمايش و كنترل، تفاوت جندانى با
جز داروهاى مرتبط با بيمارى كه توسط متخصص جراحى مغز تجويز كرديده بود، هيج مداخله درمانى و توانبخشى ديكرى دريافت نكرده

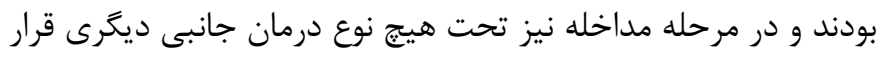

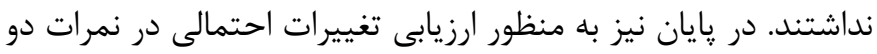

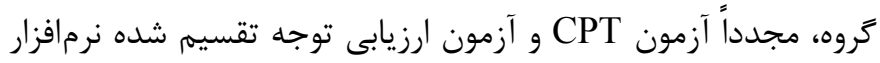

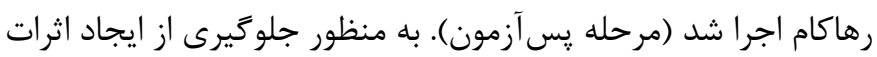

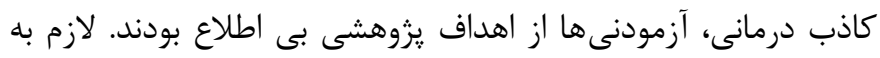
ذكر است فرايند مداخله براى بازيابى فرآيند توجه، يك راهبرد ترميم آنها با استفاده از تمرين تكرارى، اجرا و بعد از انجام موفقيتآميز تكليف،

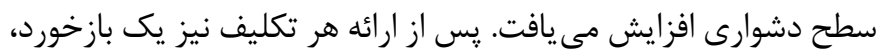
توسط نرمافزار به بيمار داده مى شد. همجنين در پايان هر جلسه يك

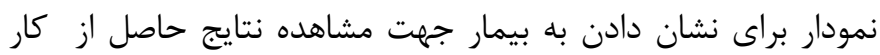

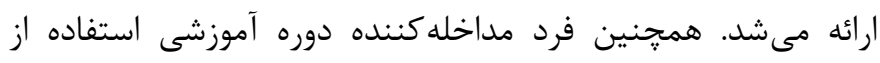

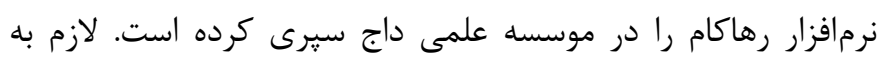

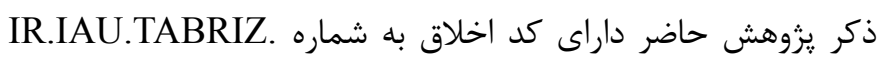

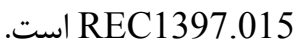
نرمافزار توانبخشى شناختى رهاكام: اين نرمافزار يك بسته توانبخشى شناختى است كه براى بازگرداندن توانايى هاى شناختى در افرادى كه دجار آسيب مغزى شدهاند در اوايل دهه • •99 آتوسعه يافت.

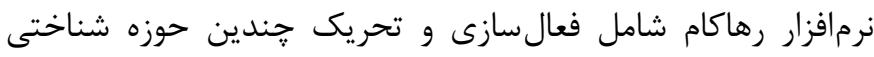

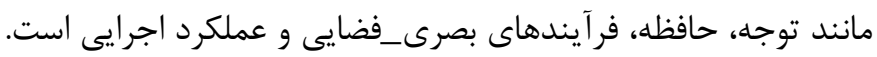

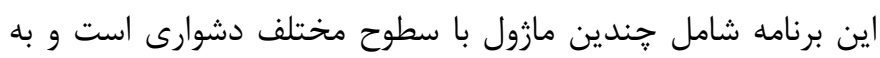

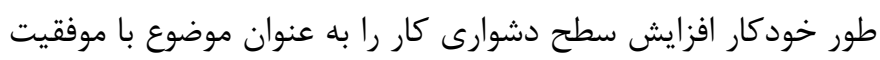

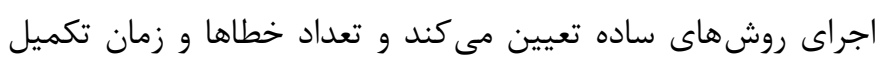

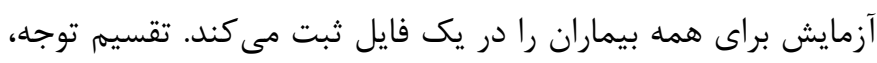
تمركز، واكنش زمان، حافظه لغتى، حافظه كلامى (يعنى كل متن، نه تنها كلمات فردى)، حافظه فضايى زير مجموعه اين نرمافزار مى باشد. برنامه رهاكام انعطاف يذيرى، سادگى، دسترسى، ديناميك و عينيتى

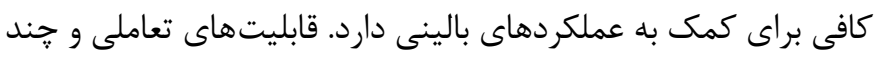

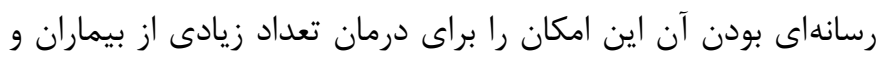

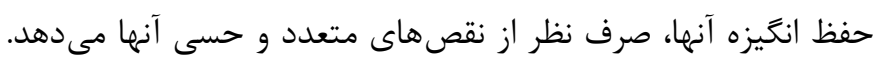

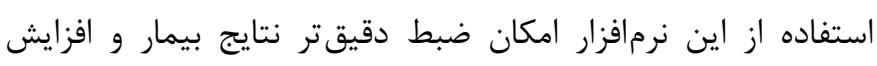

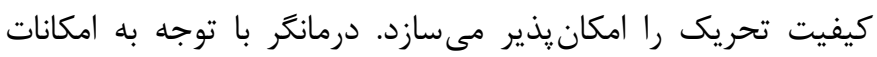
غربال گرى ميزان عملكرد شخص را اندازهَيرى مى كند. رهاكام، 9 مازول غربال كرى براى آزمون عملكردهاى شناختى بيشنهاد مى دهدي.

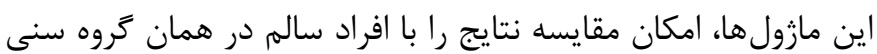

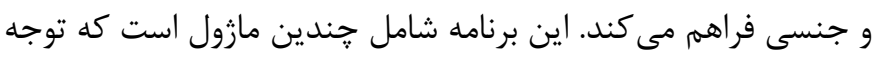


جدول 1. يافته هاى جمعيتشناختى به تفكيك دامنه سنى و سطح هوشيارى گروه نمونه

\begin{tabular}{|c|c|c|c|c|c|}
\hline تعداد & درصد & فراوانى & تروه & مولفه & متغير \\
\hline \multirow{2}{*}{$r}$. & $\Delta \cdot$ & $r \cdot$ & آزمايش & \multirow{2}{*}{ مرد } & \multirow{5}{*}{ جنسيت } \\
\hline & $r \Delta$ & 1. & كنترل & & \\
\hline \multirow{2}{*}{$r}$. & $\mid r / \Delta$ & $\Delta$ & آزمايش & \multirow{2}{*}{ زن } & \\
\hline & $1 T / Q$ & $\Delta$ & كنترل & & \\
\hline r. & $1 \ldots$ & r. & & تعداد كل & \\
\hline \multirow[b]{2}{*}{$r}$. & $r V / Q$ & 10 & آزمايش & \multirow{2}{*}{ زير دييلم } & \multirow{5}{*}{ ميزان تحصيلات } \\
\hline & $r \Delta$ & 1. & كنترل & & \\
\hline \multirow{2}{*}{$r}$. & $\mid r / \Delta$ & $\Delta$ & آزمايش & \multirow{2}{*}{ تحصيلات } & \\
\hline & $r \Delta$ & 1. & كنترل & & \\
\hline r. & $1 \cdots$ & r. & & تعداد كل & \\
\hline \multirow{2}{*}{$r \cdot$} & $\mid r / \Delta$ & $\Delta$ & آزمايش & \multirow{2}{*}{$M \Lambda-Y F$} & \multirow{9}{*}{ دامنه سنى } \\
\hline & $\mid r / Q$ & $\Delta$ & كنترل & & \\
\hline \multirow{2}{*}{$r \cdot$} & $\mid r / \Delta$ & $\Delta$ & آزمايش & \multirow{2}{*}{$r \Delta-r}$. & \\
\hline & $r \cdot$ & $\wedge$ & كنترل & & \\
\hline \multirow{2}{*}{$r}$. & 10 & 9 & آزمايش & \multirow{2}{*}{ Ml-ra } & \\
\hline & $V / Q$ & r & كنترل & & \\
\hline \multirow{2}{*}{$r$. } & 1. & r & آزمايش & \multirow{2}{*}{$r q-p}$. & \\
\hline & 1. & r & كنترل & & \\
\hline r. & $1 \ldots$ & r. & & تعداد كل & \\
\hline \multirow{2}{*}{$r}$. & $V / \Delta$ & r & آزمايش & \multirow{2}{*}{9} & \multirow{13}{*}{ سطح هوشيارى } \\
\hline & 1. & r & كنترل & & \\
\hline \multirow{2}{*}{$r}$. & $\mid r / Q$ & $\Delta$ & آزمايش & \multirow{2}{*}{1.} & \\
\hline & 1. & r & كنترل & & \\
\hline \multirow{2}{*}{$r}$. & $V / Q$ & r & آزمايش & \multirow{2}{*}{11} & \\
\hline & $\mid r / \Delta$ & $\Delta$ & كنترل & & \\
\hline \multirow{2}{*}{$r}$. & 1. & r & آزمايش & \multirow{2}{*}{ ir } & \\
\hline & $V / \Delta$ & $r$ & كنترل & & \\
\hline \multirow{2}{*}{$r \cdot$} & $V / \Delta$ & r & آزمايش & \multirow{2}{*}{ س } & \\
\hline & $\Delta$ & r & كنترل & & \\
\hline$r$ & $\Delta$ & r & آزمايش & & \\
\hline 1 & $\Delta$ & $r$ & كنترل & if & \\
\hline r. & $1 \cdots$ & r. & & تعداد كل & \\
\hline
\end{tabular}


با توجه به جدول كا، يافتهاى توصيفى يزوهش نشان مىدهد كه تغييراتى داشته است كه به منظور بررسى اين تغييرات از روش تحليل

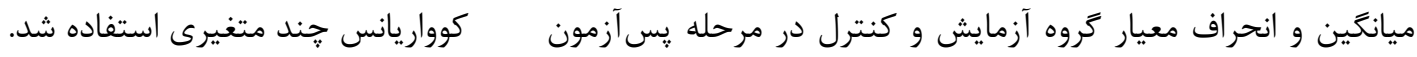

جدول r. يافته هاى توصيفى

\begin{tabular}{|c|c|c|c|c|c|}
\hline تعداد كل & انحراف معيار & ميانگين & كروه & متغير & 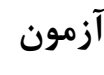 \\
\hline \multirow{2}{*}{$r \cdot$} & 1/ब9 & $-r / T$. & 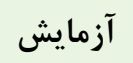 & \multirow{2}{*}{ بيش آزمون توجه تقسيمشده } & \multirow{4}{*}{$\begin{array}{l}\frac{2}{2} \\
\frac{2}{2} \\
\frac{2}{3} \\
\frac{3}{2}\end{array}$} \\
\hline & $1 / \cdot r$ & $-r / 1 \cdot$ & كنترل & & \\
\hline \multirow{2}{*}{$r \cdot$} & 1/94 & $1 / \cdot 0$ & 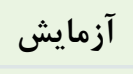 & \multirow{2}{*}{ پِ آزمون توجه تقسيمشده } & \\
\hline & $1 / 4 V$ & $-1 / 4$ & 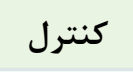 & & \\
\hline \multirow{2}{*}{$r \cdot$} & $1 / \pi \Delta$ & $\Delta / G$. & 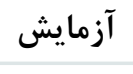 & \multirow{2}{*}{ بيش آزمون خطاى حذف محرى } & \multirow{8}{*}{ 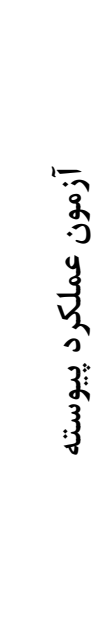 } \\
\hline & $1 / 14$ & $\Delta / \cdot \Delta$ & كنترل & & \\
\hline \multirow{2}{*}{$r \cdot$} & $\cdot / v a$ & $f / 9$. & 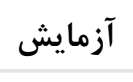 & \multirow{2}{*}{ يس آزمون خطاى حذف محرى } & \\
\hline & $.19 V$ & $\Delta / / \Delta$ & 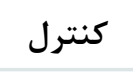 & & \\
\hline \multirow{2}{*}{$r \cdot$} & $1 / \Delta \Delta$ & $8 / 1$. & 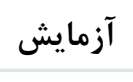 & \multirow{2}{*}{ پيش آزمون خطاى ارائه پِاسخ } & \\
\hline & $1 / / 4$ & $\Delta / \Delta \Delta$ & 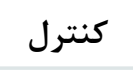 & & \\
\hline \multirow{2}{*}{$r \cdot$} & $1 / \pi 9$ & $\Delta / \cdot \cdot$ & 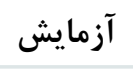 & \multirow{2}{*}{ پس آزمون خطاى ارائه ياسخ } & \\
\hline & $1 / 0$ & $\Delta / 1$. & كنترل & & \\
\hline
\end{tabular}

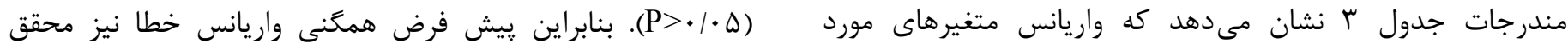
شده است و مى توان از روش تحليل كوواريانس جند متغيرى استفاده

بررسى در دو گروه همگن است. ترا كه F مشاهده شده مربوط به اين آزمون، در متغيرهاى مورد بررسى از نظر آمارى معنادار نيست كرد.

جدول r. نتايج آزمون لون براى بررسى بيش فرض همغنى واريانسها

\begin{tabular}{|c|c|c|c|c|}
\hline $\mathbf{P}$ & درجه آزادى دوم & درجه آزادى اول & 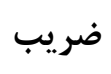 & متغير \\
\hline $\mathrm{P}>\cdot 1 \cdot 0$ & ru & 1 & $\cdot 1 \cdot .1$ & نوجه تقسيم شده (نرمافزار رهاكام) \\
\hline $\mathrm{P}>\cdot / \cdot \Delta$ & rی & 1 & $1 / \cdot 9$ & خطاى حذف محرى (آزمون CPT) \\
\hline $\mathrm{P}>\cdot 1 \cdot 0$ & rs & 1 & $\cdot / / \Delta V$ & خطاى ارائه پاسخ (آزمون CPT) \\
\hline
\end{tabular}

مندرجات جدول ه نشان مى دهد كه F مشاهده شده در سطح گروهى

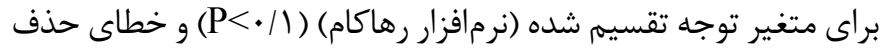

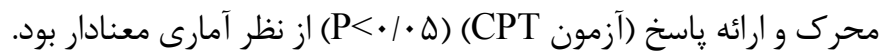
با توجه به ميانگين نمرات دو كروه در جدول يافتههاى توصيفى (جدول (1)، مشاهده مىشود كه ميانكَين نمرات متغير توجه تقسيم شده (نرمافزار
با توجه به مندرجات جدول عا، تفاوتهاى موجود در توجه تقسيم شده (نرمافزار رهاكام) و همجنين خطاى حذف محرك و خطاى ارائه پِاسخ به

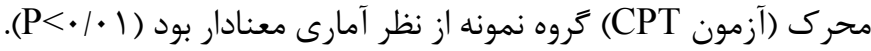

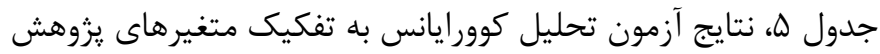

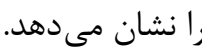


يافته است. اين يافته بدان معناست كه با افزايش نمرات توجه تقسيم شده رهاكام) در گروه آزمايش نسبت به كروه كنترل در مرحله يس آزمون افزايش

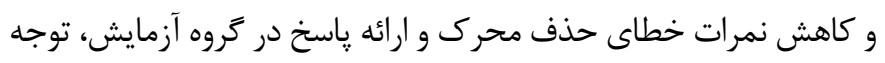
و ميانكين نمرات دو متغير خطاى حذف محرك و و ارائه ياسخ (آزمون تقسيم شده و مداوم اين گروه نسبت به كروه كنترل بهبود يافته است.

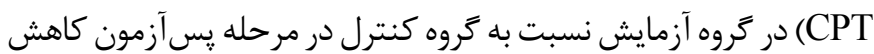

جدول ؟ا. نتايج تحليل كوواريانس خند متغيرى توجه

\begin{tabular}{|c|c|c|c|c|c|c|c|}
\hline $\mathbf{P}$ & \multicolumn{2}{|c|}{$\mathbf{F}$} & درجه آزادى خطا & \multicolumn{2}{|c|}{ درجه آزادى فرضيه } & 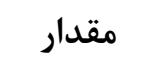 & 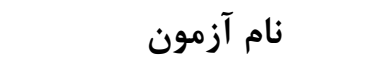 \\
\hline $.1 \cdot .1$ & \multicolumn{2}{|c|}{9199} & rr & \multicolumn{2}{|c|}{ r } & $\cdot / \mathrm{rV}$ & اثر بيلايى \\
\hline$\cdot 1 \cdot .1$ & \multicolumn{2}{|c|}{9199} & r & \multicolumn{2}{|c|}{ r } & 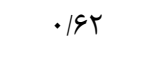 & 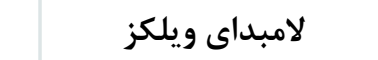 \\
\hline \multicolumn{8}{|c|}{ جدول ه. نتايج آزمون تحليل كوواريانس به تفكيك متغيرهاى يروهش } \\
\hline ضريب إِا & $\mathbf{P}$ & $\mathbf{F}$ & مجذانغين & df & مجذوروات & متغير & 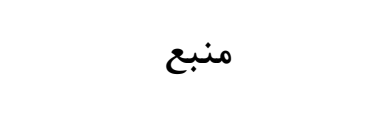 \\
\hline \multirow[t]{2}{*}{$\cdot \operatorname{lr}$} &.$\cdot .1$ & 1.1 .9 & $|F / V|$ & 1 & $|F / N|$ & مقدار ثابت & \multirow{2}{*}{ يس آزمون توجه تقسيمشده } \\
\hline & & & $1 / 48$ & ra & Q1/19 & خطا & \\
\hline \multirow[t]{2}{*}{. } & $\cdot / \cdot \Delta$ & $\Delta / r v$ & $r / 9 \Lambda$ & 1 & $r / 9 \Lambda$ & مقدار ثابت & \multirow{2}{*}{ محرى (آزمون خطاى حذف } \\
\hline & & & $\cdot 10$ & ra & IV/a. & خطا & \\
\hline \multirow[t]{2}{*}{$\cdot 110$} & $\cdot 1 \cdot \Delta$ & $9 / 49$ & N/99 & 1 & N/99 & مقدار ثابت & \multirow{2}{*}{$\begin{array}{l}\text { يس آزمون خطاى ارائه پاسخ } \\
\text { (آزمون CPT }\end{array}$} \\
\hline & & & $1 / 4$. & ra & $r q / \cdot v$ & خطا & \\
\hline
\end{tabular}

تقسيم شده و مداوم بيماران مبتلا به آسيب تروماتيك مغزى دارد. يافته هاى اين يزوهش با نتايج دو مطالعه Fernandez و همكاران (• (1، ه 1) و مطالعه Pantzartzidou و همكاران (1) همسو مىباشد.

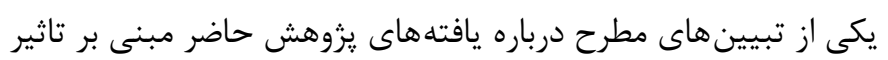

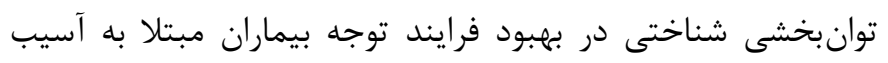

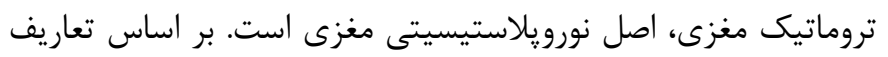

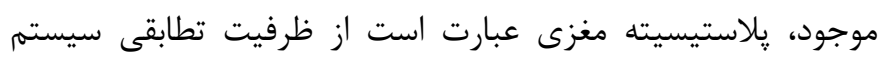

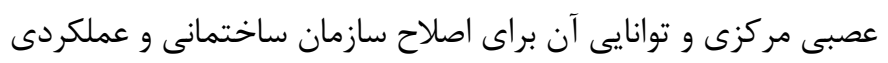

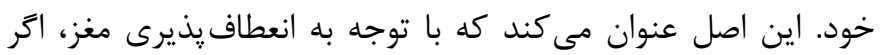
نورونهاى موجود در مناطق مغزى مختلف كه به هر دليلى كزكار هستند به طور مناسب و مكرر تحريك شوند، مى توان تغييرات مناسبى

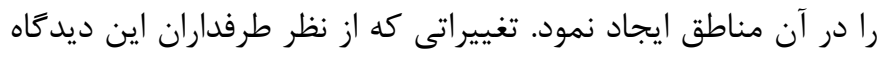

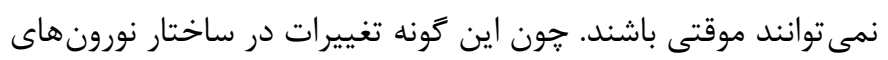

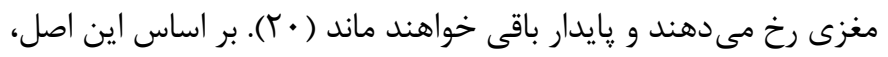

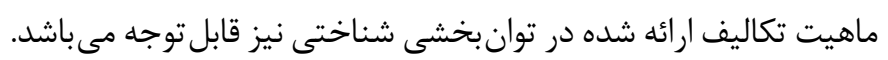

با توجه به ميانگين نمرات دو گروه در جدول يافتههاى توصيفى (جدول ()، مشاهده مىشود كه ميانگين نمرات متغير توجه تقسيم شده (نرمافزار رهاكام) در گروه آزمايش نسبت به گروه كنترل در مرحله

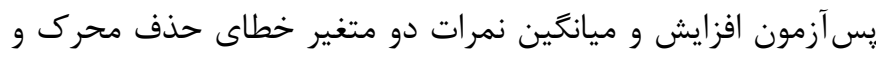

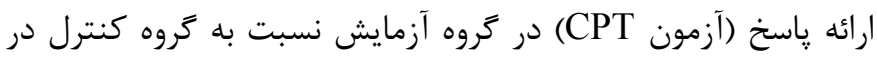

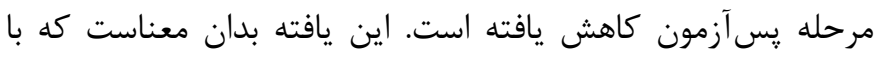

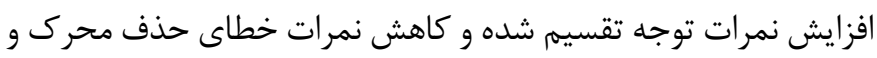

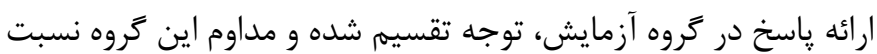
به كروه كنترل بهبود يافته است.

يروهش حاضر با هدف بررسى تاثير توانبخشى شناختى با نرمافزار

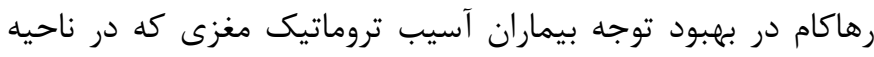

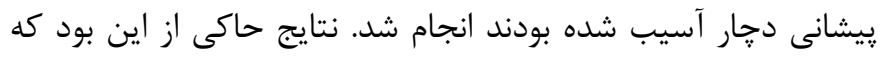

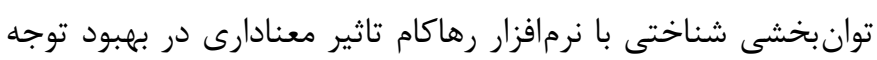


آزمودنى هاى خود و با استفاده از MRI نشان دادند.

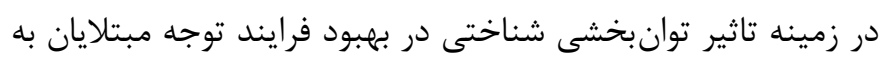

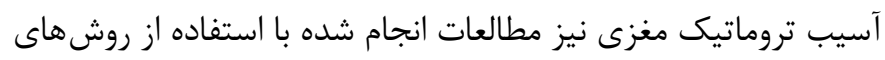

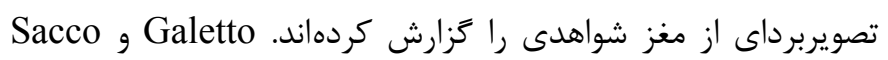

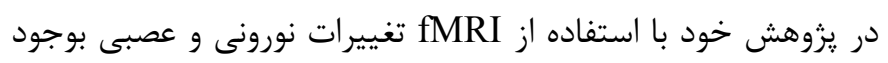

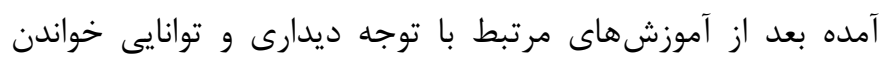

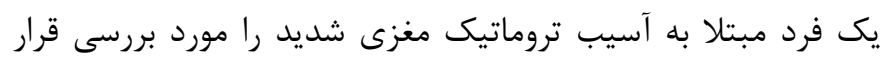

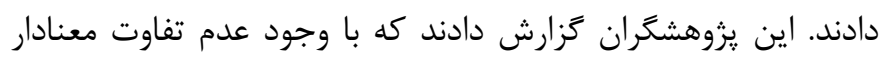

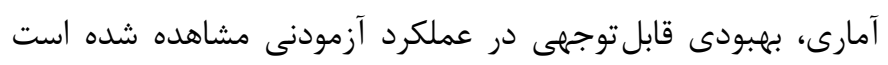

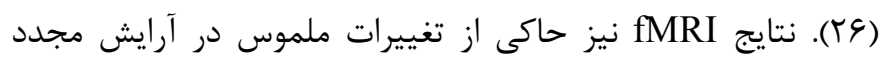

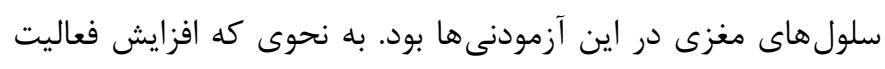

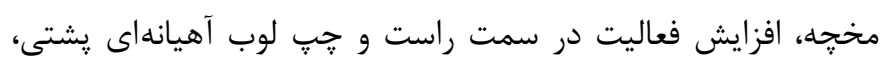

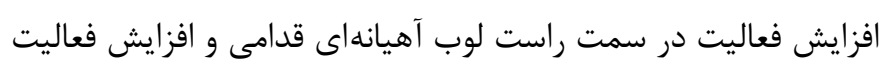

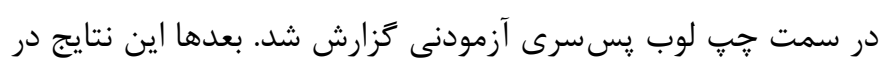

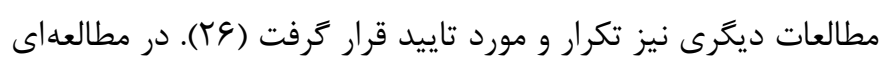

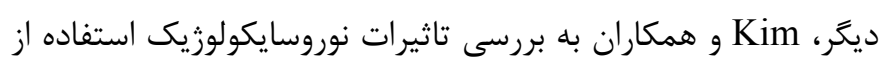

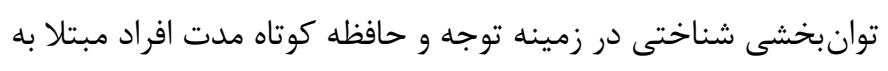

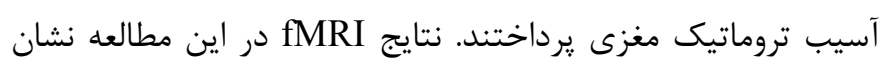

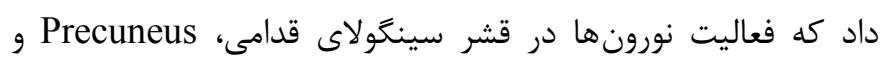

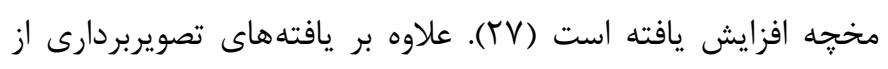

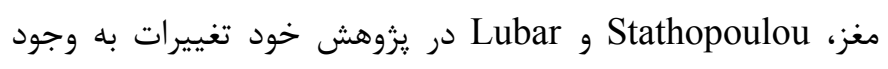

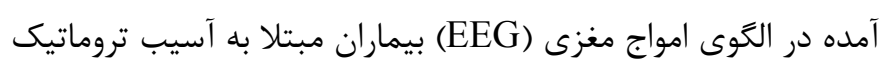

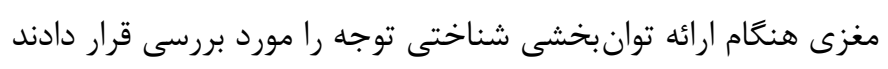

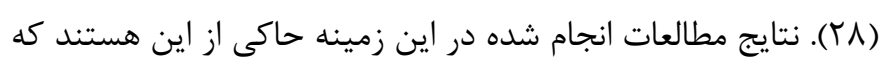

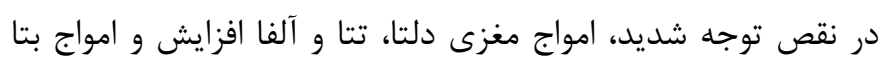

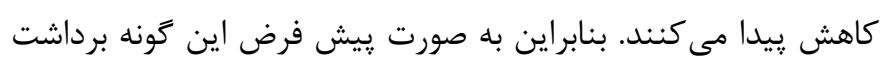

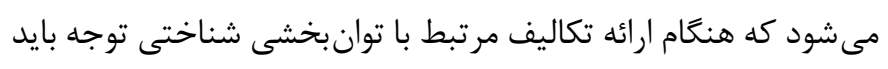

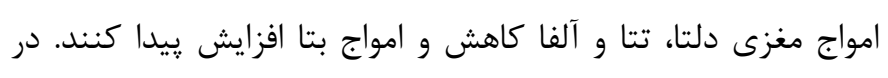

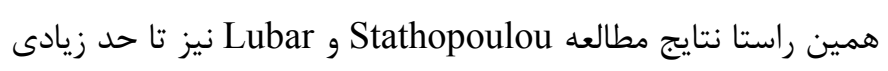

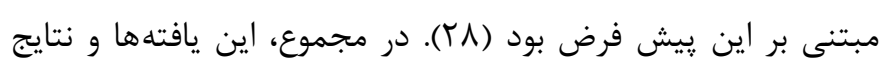

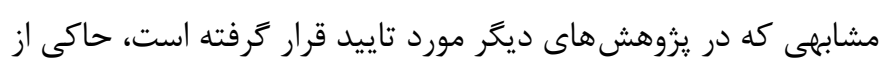

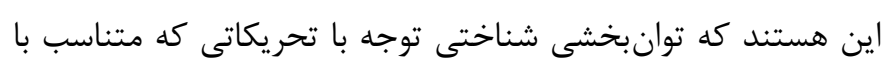

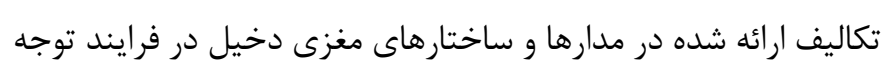

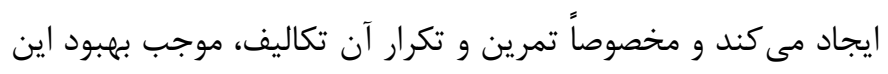

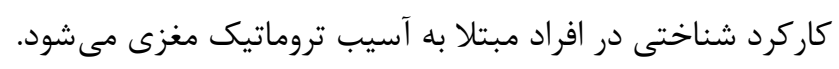

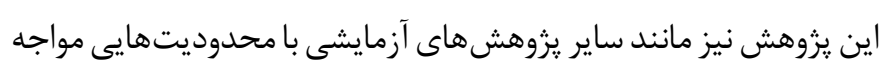

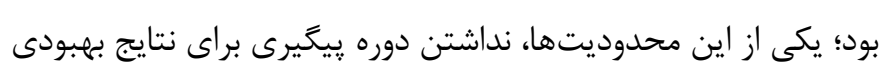

به نحوى كه Mala و Wilms در مطالعه خود عنوان مى كنند ماهيت

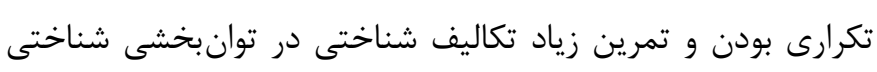

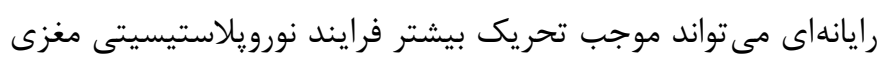

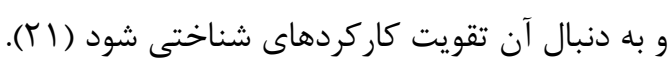

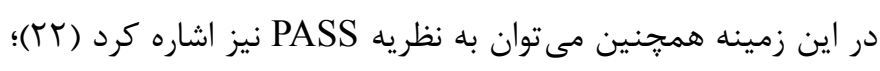

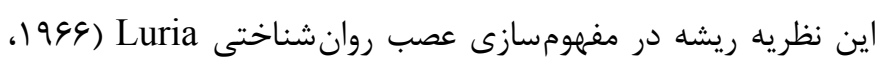

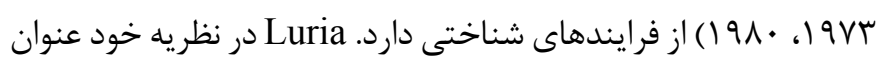

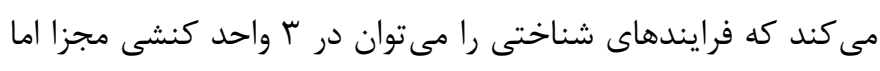
مرتبط با هم مفهومسازى كرد كه واحد نخست، فرايند شناختى توجه

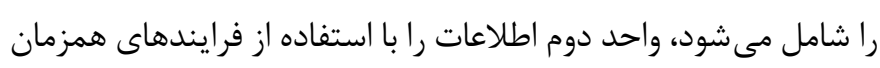

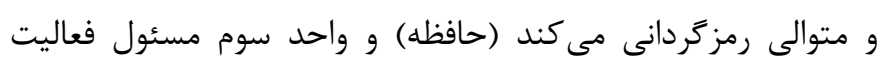

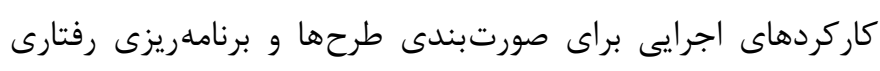

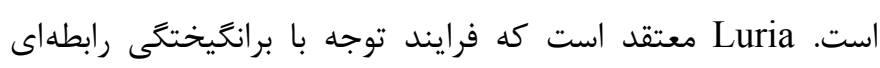
سلسلهمراتبى دارند، به نحوى كه وقتى برانگيختكى (هوشيارى) مختل

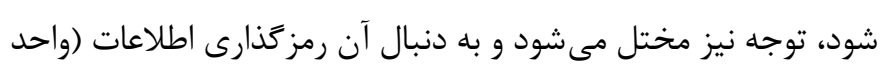

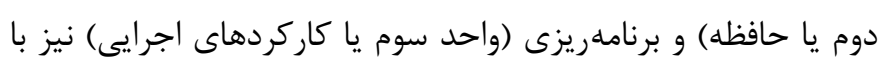

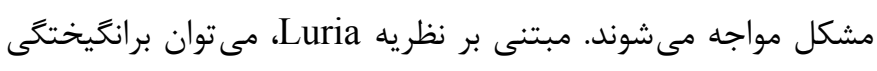

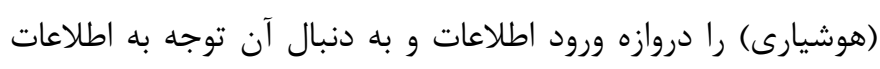

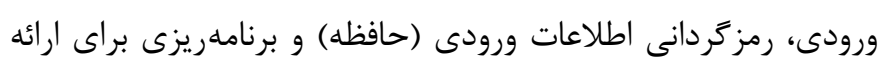

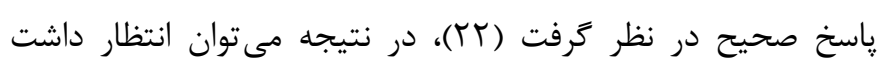

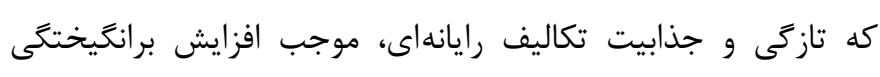

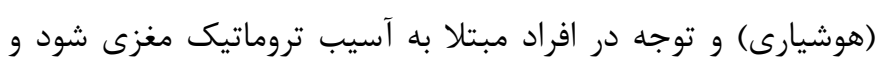

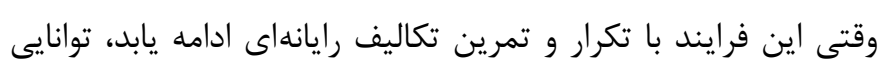
توجه را بهبود ببخشد.

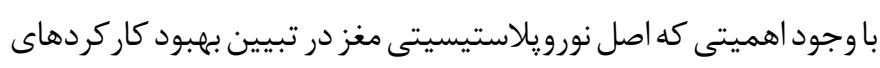
شناختى حاصل از توانبخشى دارد، ولى در توضيح ماهيت و جلَّونكى

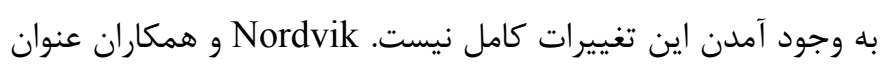

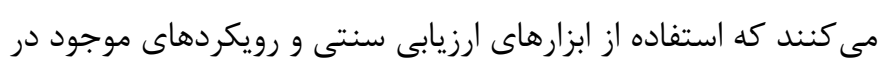

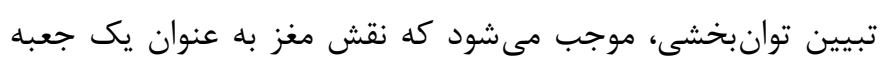

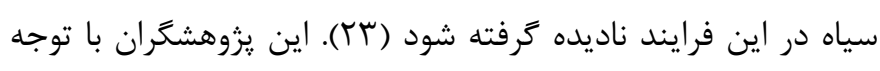

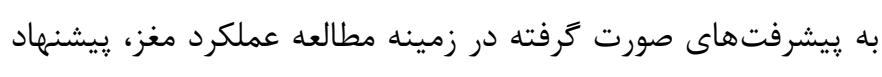

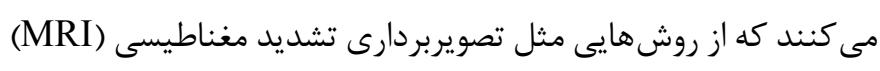

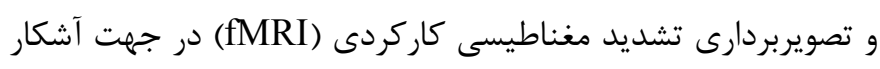

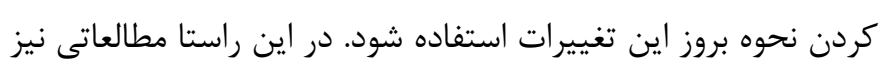

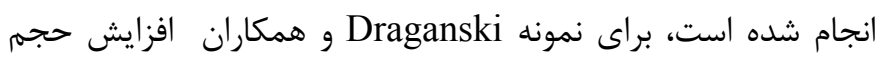

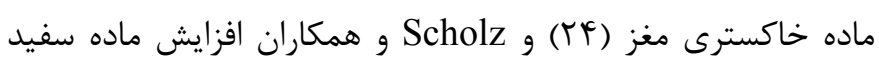

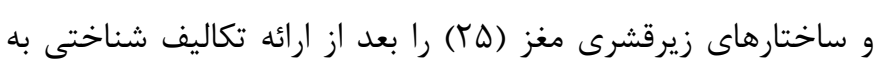




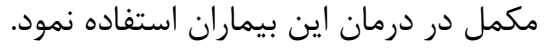

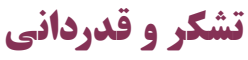

اين يزوهش برگرفته از يايان نامه دانشجويى كارشناس ارشد روان شناسى

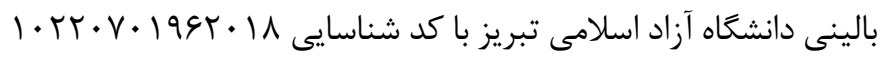
مىباشد و نويسندكان بدين وسيله از كليه افرادى كه در انجام اين مطالعه همكارى داشتند، تشكر و قدردانى مى كنند. همجنين از شركت داج براى در اختيار گذاشتن اين نرمافزار قدردانى مى گردد.

\section{References}

1. Dewan MC, Rattani A, Gupta S, Baticulon RE, Hung YC, Punchak M, et al. Estimating the global incidence of traumatic brain injury. Journal of Neurosurgery. 2018;130(4):1080-1097.

2. Dang B, Chen W, He W, Chen G. Rehabilitation treatment and progress of traumatic brain injury dysfunction. Neural Plasticity. 2017;2017.

3. Naseri Qara FZ, Shafizad M, Hosseini SH. Relationship between depression after traumatic brain injury and demographic characteristics in a three-year follow-up. Journal of Mazandaran University of Medical Sciences. 2018;27(157):133-143.

4. Soberg HL, Røe C, Anke A, Arango-Lasprilla JC, Skandsen $\mathrm{T}$, Sveen U, et al. Health-related quality of life 12 months after severe traumatic brain injury: a prospective nationwide cohort study. Journal of Rehabilitation Medicine. 2013;45(8):785-791.

5. Hibbard MR, Gordon WA, Othera L. Traumatic brain injury. In Dattilio FM, Freeman A, editors. Cognitive-behavioral strategies in crisis intervention. 3rd ed. New York:Guilford;2000. pp. $219-42$

6. Beaulieu-Bonneau S, Fortier-Brochu E, Ivers H, Morin CM. Attention following traumatic brain injury: Neuropsychological and driving simulator data, and association with sleep, sleepiness, and fatigue. Neuropsychological Rehabilitation. 2017;27(2):216-238.

7. Richard NM, O’Connor C, Dey A, Robertson IH, Levine B. External modulation of the sustained attention network in trau

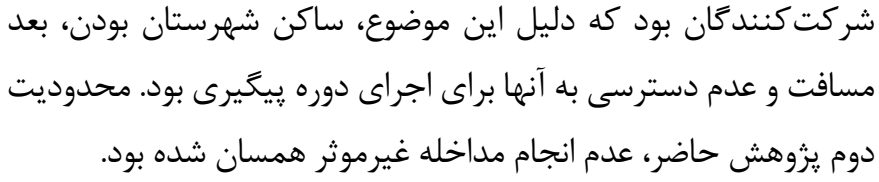

matic brain injury. Neuropsychology. 2018;32(5):541-553.

8. Maggio MG, De Luca R, Molonia F, Porcari B, Destro M, Casella $\mathrm{C}$, et al. Cognitive rehabilitation in patients with traumatic brain injury: A narrative review on the emerging use of virtual reality. Journal of Clinical Neuroscience. 2019;61:1-4. 9. Sigmundsdottir L, Longley WA, Tate RL. Computerised cognitive training in acquired brain injury: A systematic review of outcomes using the International Classification of Functioning (ICF). Neuropsychological Rehabilitation. 2016;26(5-6):673-741.

10. Fernandez E, Bergado Rosado JA, Rodriguez Perez D, Salazar Santana S, Torres Aguilar M, Bringas ML. Effectiveness of a computer-based training program of attention and memory in patients with acquired brain damage. Behavioral Sciences. 2018;8(1):4.

11. Pantzartzidou A, Dionyssiotis Y, Stefas E, Samlidi E, Georgiadis T, Kandylakis E. Rehacom software application is effective in cognitive rehabilitation of patients with brain injuries. Physical Medicine and Rehabilitation Research. 2017;2(1):1-4. 12. Bogdanova Y, Yee MK, Ho VT, Cicerone KD. Computerized cognitive rehabilitation of attention and executive function in acquired brain injury: A systematic review. The Journal of Head Trauma Rehabilitation. 2016;31(6):419-433.

13. Mohammadi MR, Keshavarzi Z, Talepasand S. The effectiveness of computerized cognitive rehabilitation training program in improving cognitive abilities of schizophrenia clients. 
Iranian Journal of Psychiatry. 2014;9(4):209-215.

14. Amiri S, Nasehi M, Hasani Abharian P, Haji Naghi Tehrani

Kh, Kazemi R. Effectiveness of Rehacom cognitive rehabilitation software on depression in patients with chronic stroke. Military Caring Sciences. 2019;6(1):39-48. (Persian)

15. Fernandez E, Bringas ML, Salazar S, Rodriguez D, Garcia ME, Torres M. Clinical impact of RehaCom software for cognitive rehabilitation of patients with acquired brain injury. MEDICC Review. 2012;14(4):32-35

16. Nordvik JE, Walle KM, Nyberg CK, Fjell AM, Walhovd KB, Westlye LT, et al. Bridging the gap between clinical neuroscience and cognitive rehabilitation: The role of cognitive training, models of neuroplasticity and advanced neuroimaging in future brain injury rehabilitation. NeuroRehabilitation. 2014;34(1):81-85.

17. Barbu MC, Furlong RM, Poveda B, Scotland J. Attention and working memory training: The effect of rehacom software on cognitive skills in a non-clinical sample. Psychology and Behavioral Science International Journal. 2017;4(3):1-11.

18. Rosvold HE, Mirsky AF, Sarason I, Bransome Jr ED, Beck LH. A continuous performance test of brain damage. Journal of Consulting Psychology. 1956;20(5):343-350.

19. Hadianfard H, Najarian B, Shokrkon H, Mehrabizadeh Honarmand M. Construction and validation of the Farsi version of the continuous performance test. Quarterly Journal of Psychology. 2001;4(4):388-404.

20. Fuchs E, Flugge G. Adult neuroplasticity: More than 40 years of research. Neural Plasticity. 2014;2014.

21. Wilms I, Mala H. Indirect versus direct feedback in computer-based Prism Adaptation Therapy. Neuropsychological
Rehabilitation. 2010;20(6):830-853.

22. Naglieri JA, Das J. Planning, attention, simultaneous, successive (PASS) theory: A revision of the concept of intelligence. In Flanagan DP, Harrison PL, editors. Contemporary intellectual assessment: Theories, tests, and issues. New York:The Guilford Press;2005. pp. 120-135.

23. Nordvik JE, Walle KM, Nyberg CK, Fjell AM, Walhovd $\mathrm{KB}$, Westlye LT, et al. Bridging the gap between clinical neuroscience and cognitive rehabilitation: The role of cognitive training, models of neuroplasticity and advanced neuroimaging in future brain injury rehabilitation. NeuroRehabilitation. 2014;34(1):81-85.

24. Draganski B, Gaser C, Busch V, Schuierer G, Bogdahn U, May A. Neuroplasticity: Changes in grey matter induced by training. Nature. 2004;427(6972):311-312.

25. Scholz J, Klein MC, Behrens TE, Johansen-Berg H. Training induces changes in white-matter architecture. Nature Neuroscience. 2009;12(11):1370-1371.

26. Galetto V, Sacco K. Neuroplastic changes induced by cognitive rehabilitation in traumatic brain injury: A review. $\mathrm{Neu}$ rorehabilitation and Neural Repair. 2017;31(9):800-813.

27. Kim J, Whyte J, Patel S, Europa E, Slattery J, Coslett HB, et al. A perfusion fMRI study of the neural correlates of sustained-attention and working-memory deficits in chronic traumatic brain injury. Neurorehabilitation and Neural Repair. 2012 Sep;26(7):870-880.

28. Stathopoulou S, Lubar JF. EEG changes in traumatic brain injured patients after cognitive rehabilitation. Journal of Neurotherapy. 2004;8(2):21-51. 